Check for updates

Cite this: RSC Adv., 2019, 9, 20415

Received 24th May 2019

Accepted 12th June 2019

DOI: 10.1039/c9ra03931g

rsc.li/rsc-advances

\section{Highly effective transformation of methyl phenyl carbonate to diphenyl carbonate with recyclable $\mathrm{Pb}$ nanocatalyst $\uparrow$}

\author{
Songlin Wang, ${ }^{\text {ab }}$ Hongying Niu, ${ }^{a}$ Jianji Wang, ${ }^{b}$ Tong Chen, (D) *c Gongying Wang ${ }^{c}$ \\ and Jiamin Zhang ${ }^{a}$
}

Diphenyl carbonate (DPC) is a type of versatile industrial chemical, and the disproportionation of methyl phenyl carbonate (MPC) is a key step to produce DPC. However, the design and formulation of a catalyst for the efficient synthesis of DPC is a major challenge due to its small equilibrium constant. The support material is a critical factor influencing the performance of $\mathrm{Pb}$ nanocatalysts. Thus, a series of $\mathrm{Pb}$-based catalysts over $\mathrm{MgO}, \mathrm{ZrO}_{2}, \mathrm{SiO}_{2}, \mathrm{TiO}_{2}$ and $\mathrm{Al}_{2} \mathrm{O}_{3}$ were prepared to investigate the effect of the support materials on the physicochemical properties and catalytic performances for the conversion of MPC to effectively synthesize DPC. The catalysts were well characterized by XRD, BET, TEM, XPS, ICP-OES, $\mathrm{H}_{2}^{-}$ TPR, Py-IR and $\mathrm{NH}_{3}-T P D$. The results showed that the nature of the support obviously affected the structural properties and catalytic performances, and $\mathrm{Pb}$ was dispersed better on $\mathrm{SiO}_{2}, \mathrm{TiO}_{2}, \mathrm{ZrO}_{2}$ and $\mathrm{MgO}$ than on $\mathrm{Al}_{2} \mathrm{O}_{3}$, and showed stronger metal-support interaction over $\mathrm{MgO}$ and $\mathrm{ZrO}_{2}$. The activity results revealed that $\mathrm{PbO} / \mathrm{MgO}$ and $\mathrm{PbO} / \mathrm{ZrO}_{2}$ exhibited higher catalytic activities because they contained higher $\mathrm{Pb}$ dispersion and more Lewis acid sites, and the catalytic activities followed the order $\mathrm{PbO} / \mathrm{MgO}>\mathrm{PbO} / \mathrm{ZrO}_{2}>\mathrm{PbO} / \mathrm{SiO}_{2}>\mathrm{PbO} / \mathrm{Al}_{2} \mathrm{O}_{3}>\mathrm{PbO} / \mathrm{TiO}_{2}$. On the contrary, $\mathrm{PbO} / \mathrm{MgO}$ and $\mathrm{PbO} / \mathrm{ZrO}_{2}$ exhibited better reusability due to strong interaction between the highly dispersed $\mathrm{Pb}$ and the supports, and the activity decrease in the case of $\mathrm{PbO} / \mathrm{SiO}_{2}, \mathrm{PbO} / \mathrm{Al}_{2} \mathrm{O}_{3}$ and $\mathrm{PbO} / \mathrm{TiO}_{2}$ mainly resulted from the $\mathrm{Pb}$ leaching loss. This work would contribute to exploiting novel catalytic materials in a wide range of applications for the efficient synthesis of organic carbonates.

\section{Introduction}

Due to its outstanding electrical, mechanical and heat resistance properties, polycarbonate (PC), as an important engineering thermoplastic for ubiquitous applications in several industries (automobiles, office equipment, medical devices, etc.), has attracted considerable interest in the last decades., ${ }^{\mathbf{1 , 2}}$ Diphenyl carbonate (DPC), a building block, was often employed for the phosgene-free synthesis of PC by melt transesterification with bisphenol-A, and was also used for the production of pharmaceuticals, polymer materials, fine chemicals, etc. ${ }^{3-5}$ It was, therefore, necessary to develop efficient and environmentally benign synthetic routes to replace the highly toxic synthesis via phosgene. Among the alternative routes

${ }^{a}$ School of Chemistry and Chemical Engineering, Henan Institute of Science and Technology, Xinxiang 453003, P. R. China. E-mail: wangsonglin2009@163.com ${ }^{b}$ Postdoctoral Programs, Key Laboratory of Green Chemical Media and Reactions, Ministry of Education, School of Chemistry and Chemical Engineering, Henan Normal University, Xinxiang 453007, P. R. China. E-mail: jwang@htu.cn

${ }^{c}$ Chengdu Institute of Organic Chemistry, Chinese Academy of Sciences, Chengdu 610041, P. R. China. E-mail: chentongw@sina.com.cn

$\dagger$ Electronic supplementary information (ESI) available. See DOI: 10.1039/c9ra03931g (phosgene method, ${ }^{6,7}$ oxidative carbonylation, ${ }^{\mathbf{8}, 9}$ transesterification, ${ }^{\mathbf{1 0 , 1 1}}$ etc.), the transesterification of phenol and dimethyl carbonate (DMC) was regarded as a most likely pathway to synthesize DPC without employing phosgene since the starting materials presented low toxicity and high biodegradability. This route consisted in two-step reaction where methyl phenyl carbonate (MPC) of the intermediate was first produced by the transesterification (Scheme 1-(1)), followed by the further transesterification reaction of MPC and phenol

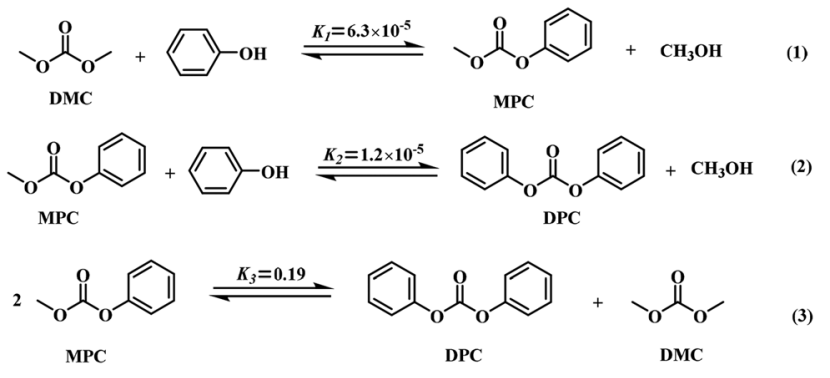

Scheme 1 Transesterification process between DMC and phenol into DPC. 
(Scheme 1-(2)) or the disproportionation of MPC (Scheme 1-(3)). Concerning the second-step reaction the equilibrium constants $K_{2}$ and $K_{3}$ indicated that DPC was mainly produced by the second step disproportionation instead of the further transesterification. ${ }^{12,13}$ On the contrary, the first step was ratedetermining step since $K_{1}$ was much lower than $K_{3}$. Hence, considerable studies on the first step transesterification have been particularly carried out, ${ }^{14-17}$ but only few efforts have been made to the second step disproportionation. ${ }^{18,19}$ Indeed, the disproportionation of MPC is also the key step to produce DPC. Overall, it is very significant to intensively study on MPC disproportionation, which is advantageous to improving the yield of DPC and the conversion of the starting materials in future industrial applications.

The disproportionation reaction suffered from the low yield and selectivity of DPC due to the relatively low equilibrium constant and reaction rate. Therefore, the development of highly active catalysts is crucial in this reaction. Among various homogeneous catalytic systems reported like organo-tin/ titanium catalysts, even though they exhibited outstanding catalytic activities, ${ }^{19,20}$ they had received little consideration because of the separation problems between DPC and the catalysts. Therefore, heterogeneous catalysis currently attracted more attention because these catalysts might be facilely recovered from the reaction mixture by simple filtration and could be recycled, making the procedure more feasible.

Recently, we studied the catalytic performances of various metal oxides including $\mathrm{TiO}_{2}, \mathrm{MoO}_{3}, \mathrm{PbO}$ and so on, ${ }^{21-23}$ and found that $\mathrm{PbO}$ was prepared into the supported $\mathrm{Pb}$ catalysts or mixed metal oxides significantly improved the catalytic activity, life time and stability. ${ }^{24,25}$ However, the nature and property of the support is often found to modify the distribution, loading, size, shape and electronic state of the active species as well as their interactions with support with some special physicalchemical properties, which is well known to strongly affect the catalytic activity and stability. ${ }^{26-31}$ Therefore, the study to investigate the structure-function relationship of the supports on $\mathrm{Pb}$-based catalysts for MPC disproportionation is very worthwhile, which is conducive to screen suitable and promising supports.

In the present work, we formulate $\mathrm{Pb}$-based catalysts by employing potential metal oxides as support phases and focus on studying the effect of various supports on the physicochemical properties of the catalysts and their catalytic performance to provide the role of support materials for developing efficient catalysis materials for MPC disproportionation to effectively synthesize DPC. Herein the Pb-based catalysts are prepared using wet-impregnation process over $\mathrm{PbO}$ loading onto $\mathrm{SiO}_{2}, \mathrm{TiO}_{2}, \mathrm{Al}_{2} \mathrm{O}_{3}, \mathrm{MgO}$ and $\mathrm{ZrO}_{2}$ supports. At the same time, the catalysts are thoroughly characterized by X-ray diffraction (XRD), temperature programmed reduction of $\mathrm{H}_{2}$ $\left(\mathrm{H}_{2}\right.$-TPR), transmission electron microscopy (TEM), X-ray photoelectron spectrum (XPS), $\mathrm{N}_{2}$ adsorption/desorption measurement, pyridine-infrared spectroscopy (Py-IR) and temperature programmed desorption of $\mathrm{NH}_{3}\left(\mathrm{NH}_{3}\right.$-TPD) to clarify the support role on the Pb-based catalysts. In addition, the stabilities of these catalysts are also investigated in detail.

\section{Experimental section}

\subsection{Material preparation}

All chemicals adopted in this work were analytical purity, which were purchased from Sinopharm Chemical Reagent Co., Ltd and were directly used as received without further purification. Deionized water was used in all experimental synthesis procedures as needed.

Pure $\mathrm{SiO}_{2}$ was synthesized by sol-gel process. For this preparation, the desired amounts of tetraethyl orthosilicate, ethanol and distilled water were mixed together at room temperature. Then the ammonium aqueous solution was added gradually into the above solution under stirring at $50{ }^{\circ} \mathrm{C}$ to generate a transparent gel. The obtained gel was aged at $50{ }^{\circ} \mathrm{C}$ overnight, dried at $110^{\circ} \mathrm{C}$ for $12 \mathrm{~h}$ and subsequently calcinated $550{ }^{\circ} \mathrm{C}$ for $5 \mathrm{~h}$.

Pure $\mathrm{TiO}_{2}$ was prepared by hydrolysis process. Briefly, a proper amount of tetrabutyl titanate was dissolved in ethanol, and heated up to $50{ }^{\circ} \mathrm{C}$ under stirring. Then, appropriate amount of water was slowly added to promote the hydrolysis and was kept for $24 \mathrm{~h}$. Finally, the sediment was filtered, washed with distilled water, and dried at $110{ }^{\circ} \mathrm{C}$ for $12 \mathrm{~h}$ and calcinated at $550{ }^{\circ} \mathrm{C}$ for $5 \mathrm{~h}$.

Pure $\mathrm{Al}_{2} \mathrm{O}_{3}$ was prepared by a precipitation process. A certain amount of aluminum nitrate nonahydrate were dissolved in the deionized water and heated slowly to $90{ }^{\circ} \mathrm{C}$. Afterwards, ammonia solution with $25 \%$ concentration was added into this solution under stirring until that the $\mathrm{pH}$ of 9-10 was reached. The as-prepared solid sediment was aged for $24 \mathrm{~h}$ and then vacuum filtered off and washed repeatedly. Finally, the obtained samples were dried at $110{ }^{\circ} \mathrm{C}$ for $12 \mathrm{~h}$ and subsequently calcinated at $550{ }^{\circ} \mathrm{C}$ for $5 \mathrm{~h}$. Likewise, pure $\mathrm{MgO}$ and $\mathrm{ZrO}_{2}$ were prepared by using the similar process, respectively.

The preparation of supported Pb-based catalysts was carried out by incipient wetness impregnation process. Briefly, $\mathrm{SiO}_{2}$, $\mathrm{TiO}_{2}, \mathrm{Al}_{2} \mathrm{O}_{3}, \mathrm{ZrO}_{2}$ and $\mathrm{MgO}$ supports were homogeneously impregnated by using the aqueous solution of lead nitrate as precursor salt at ambient temperature for $24 \mathrm{~h}$, respectively. After impregnation, the samples were dried in air at $110{ }^{\circ} \mathrm{C}$ for $12 \mathrm{~h}$, and finally calcinated at $550{ }^{\circ} \mathrm{C}$ for $5 \mathrm{~h}$. And the $\mathrm{PbO}$ loading used was $10 \mathrm{wt} \%$ for all the catalysts.

\subsection{Material characterization}

The X-ray powder diffraction (XRD) analysis was carried out on a DX-2700B diffractometer with the Ni-filtered $\mathrm{CuK} \alpha$ radiation $(1.5418 \AA)$. The X-ray tube was operated at $40 \mathrm{kV}$ and $30 \mathrm{~mA}$, and the powder diffractogram was recorded at $0.02^{\circ}$ intervals in the range of $5-90^{\circ}$ with the scanning rate of $1.2^{\circ} \mathrm{min}^{-1}$.

The determination of the elemental composition was conducted by Optima 2000 DV inductively coupled plasma-optical emission spectrometer (PerkinElmer Inc., USA).

$\mathrm{N}_{2}$ adsorption-desorption isotherms were measured at liquid nitrogen temperature $\left(-196^{\circ} \mathrm{C}\right)$ using a $3 \mathrm{H}-2000 \mathrm{PS} 2$ adsorption instrument (BeiShiDe Instrument). Before the measurements, the catalysts were pretreated at $250{ }^{\circ} \mathrm{C}$ for $6 \mathrm{~h}$ under a high vacuum environment to remove physically 
adsorbed water. The specific surface area was calculated using the Brunauer-Emmett-Teller (BET) method and the pore volume and porous distribution was derived from Barrett-Joyner-Halenda (BJH) equation.

The morphology of the catalysts was investigated by transmission electron microscopy (JEM-1011) with a field-emission gun operating at $200 \mathrm{kV}$. The samples were prepared by dropping an ethanol suspension of the powder particles on a carbon film supported copper grid.

X-ray photoelectron spectrum (XPS) was employed to detect the chemical composition and states of the atoms on the catalysts, and conducted on a ESCALAB250Xi X-ray photoelectron spectrometer with $\mathrm{C}$ as the internal standard $(\mathrm{C} 1 \mathrm{~s}=284.7 \mathrm{eV})$.

$\mathrm{H}_{2}$-TPR experiment was carried out on a Micro TP-5076 chemisorption analyzer. Prior to the reduction, the catalyst (about $50 \mathrm{mg}$ ) was pretreated in $\mathrm{N}_{2}$ stream $\left(20 \mathrm{~mL} \mathrm{~min}^{-1}\right)$ at $300{ }^{\circ} \mathrm{C}$ for $1.5 \mathrm{~h}$ and then cooled to room temperature. After that, the flowing $\mathrm{H}_{2}-\mathrm{N}_{2}$ mixture $\left(10 \% \mathrm{H}_{2}\right.$ by volume) was switched on, and the temperature was gradually increased from 50 to $800{ }^{\circ} \mathrm{C}$ with a ramp of $10{ }^{\circ} \mathrm{C} \mathrm{min}{ }^{-1}$. The $\mathrm{H}_{2}$ consumption was measured with a thermal conduction detector (TCD) that had been calibrated using the standard sample of $\mathrm{CuO}$.

The number of acid sites was determined by $\mathrm{NH}_{3}$-TPD using the same instrument as that used for $\mathrm{H}_{2}$-TPR. Before the adsorption of $\mathrm{NH}_{3}$, the sample (about $100 \mathrm{mg}$ ) was first treated at $300{ }^{\circ} \mathrm{C}$ for $1.5 \mathrm{~h}$ and then decreased to $50{ }^{\circ} \mathrm{C}$ in a $\mathrm{N}_{2}$ flow of 20 $\mathrm{mL} \mathrm{min}^{-1}$. After the saturated adsorption of $\mathrm{NH}_{3}\left(10 \mathrm{~mL} \mathrm{~min}^{-1}\right)$ at $50{ }^{\circ} \mathrm{C}$ for $30 \mathrm{~min}$, the physically adsorbed $\mathrm{NH}_{3}$ was subsequently degassed from the sample for $1 \mathrm{~h}$ under the $\mathrm{N}_{2}$ flow $(20$ $\mathrm{mL} \mathrm{min}^{-1}$ ). Finally, the sample was heated to $800{ }^{\circ} \mathrm{C}$ with a rate of $10^{\circ} \mathrm{C} \mathrm{min}{ }^{-1}$, the amounts of desorbed $\mathrm{NH}_{3}$ was monitored by the thermal conduction detector (TCD). The TPD profile was decomposed into Gaussian curves to quantify the weak, medium and strong acid sites.

Py-IR spectra were measured on a Thermo Nicolet 380 FT-IR spectrometer to determine the type of acid sites. Before the measurement, the impurity was removed from the sample under $10^{-2} \mathrm{~Pa}$ condition at $200{ }^{\circ} \mathrm{C}$ for $2 \mathrm{~h}$, and then pyridine vapor was introduced into the sample for the saturated adsorption. After the evacuation at $200{ }^{\circ} \mathrm{C}$ for $1 \mathrm{~h}$ in flowing $\mathrm{He}$ atmosphere, the Py-IR spectra were subsequently collected at room temperature.

\subsection{Catalytic reaction and the product analysis}

MPC was synthesized by the reversible disproportionation of DMC and DPC, and its purity was $99.8 \%$ determined by high performance liquid chromatography. ${ }^{20}$ In a typical experiment, the catalytic performance test of MPC was performed in a threenecked glass beaker at atmospheric pressure. MPC of $150 \mathrm{mmol}$ and a proper amount of the catalysts were placed into the beaker under a flowing nitrogen and slowly heated under vigorous stirring. When the reaction temperature was reached, it was kept for the reaction. As the reaction processed, DMC might be distilled out and continuously collected in a flask beaker to promote the equilibrium reaction towards the production of DPC. Upon the completion of the reaction, the reaction was decreased down to ambient temperature. The reaction mixture was analyzed by GC-MS instrument (HP-6890/ 5973) equipped with HP-5 capillary chromatography packed column. Subsequently, the products were quantitatively analyzed with a gas chromatograph (GC-7890A) equipped with HP-5 capillary column $(30 \mathrm{~m} \times 0.32 \mathrm{~mm} \times 0.25 \mu \mathrm{m})$ and a flame ionization detector (FID).

\section{Results and discussion}

\subsection{Characterization of the catalysts}

3.1.1 BET characterization. The BET surface area, pore volume and pore size distribution determined by nitrogen adsorption-desorption measurement for all the catalysts and their corresponding supports were listed in Table 1 . The average pore diameters for these materials were in the mesoporous range, and the surface area and pore volume of the catalysts decreased in comparison to the corresponding supports. It was noted that the $\mathrm{SiO}_{2}$ support displayed the highest BET surface area among all support materials, moreover, after impregnating, the $\mathrm{PbO} / \mathrm{SiO}_{2}$ catalyst also exhibited a larger BET specific surface area and pore volume in contrast to $\mathrm{PbO} / \mathrm{MgO}, \mathrm{PbO} /$ $\mathrm{Al}_{2} \mathrm{O}_{3}, \mathrm{PbO} / \mathrm{ZrO}_{2}$ and $\mathrm{PbO} / \mathrm{TiO}_{2}$, and the orders of both the surface area and pore volume for them were as follows: $\mathrm{PbO} /$ $\mathrm{SiO}_{2}>\mathrm{PbO} / \mathrm{ZrO}_{2}>\mathrm{PbO} / \mathrm{MgO}>\mathrm{PbO} / \mathrm{TiO}_{2}>\mathrm{PbO} / \mathrm{Al}_{2} \mathrm{O}_{3}$, in the same orders as that for the pure supports. The average pore diameters of the catalysts also decreased than those of the pure supports. This was probably due to $\mathrm{PbO}$ being dispersed on the surface of these supports or filled in the pore structure after the lead impregnating, which might result in the decrease of these textural properties.

3.1.2 XRD characterization. To detect the structures of $\mathrm{Pb}$ species on various supports, XRD measurement were performed for both the catalysts and the pure supports. As could be seen in Fig. 1, XRD patterns of pure supports exhibited their respective characteristic peaks, while there were some differences with their corresponding $\mathrm{Pb}$-based catalysts among the characteristic peaks. For instance, $\mathrm{SiO}_{2}$ exhibited a broad peak at around $22^{\circ}$, and after $\mathrm{PbO}$ loading on its surface no PbO crystalline phase diffraction peak was observed for $\mathrm{PbO} / \mathrm{SiO}_{2}$. The diffraction peak at $25.4,37.9,48.1,54.1$ and $62.5^{\circ}$ were attributed to

Table 1 Results of BET measurements for the catalysts and corresponding supports

\begin{tabular}{lllc}
\hline Catalysts & $\begin{array}{l}\text { BET surface } \\
\text { area }\left(\mathrm{m}^{2} \mathrm{~g}^{-1}\right)\end{array}$ & $\begin{array}{l}\text { Total pore volume } \\
\left(\mathrm{cm}^{3} \mathrm{~g}^{-1}\right)\end{array}$ & $\begin{array}{l}\text { Average pore } \\
\text { diameter }(\mathrm{nm})\end{array}$ \\
\hline $\mathrm{PbO} / \mathrm{MgO}$ & 34.5 & 0.157 & 9.0 \\
$\mathrm{MgO}$ & 36.9 & 0.182 & 11.3 \\
$\mathrm{PbO} / \mathrm{Al}_{2} \mathrm{O}_{3}$ & 20.7 & 0.049 & 7.9 \\
$\mathrm{Al}_{2} \mathrm{O}_{3}$ & 24.8 & 0.070 & 11.6 \\
$\mathrm{PbO} / \mathrm{ZrO}_{2}$ & 43.3 & 0.106 & 8.2 \\
$\mathrm{ZrO}_{2}$ & 44.3 & 0.098 & 8.8 \\
$\mathrm{PbO} / \mathrm{TiO}_{2}$ & 30.3 & 0.073 & 9.9 \\
$\mathrm{TiO}_{2}$ & 33.4 & 0.074 & 11.3 \\
$\mathrm{PbO} \mathrm{SiO}$ & & 11.1 \\
$\mathrm{SiO}_{2}$ & 67.3 & 0.522 & 12.3
\end{tabular}




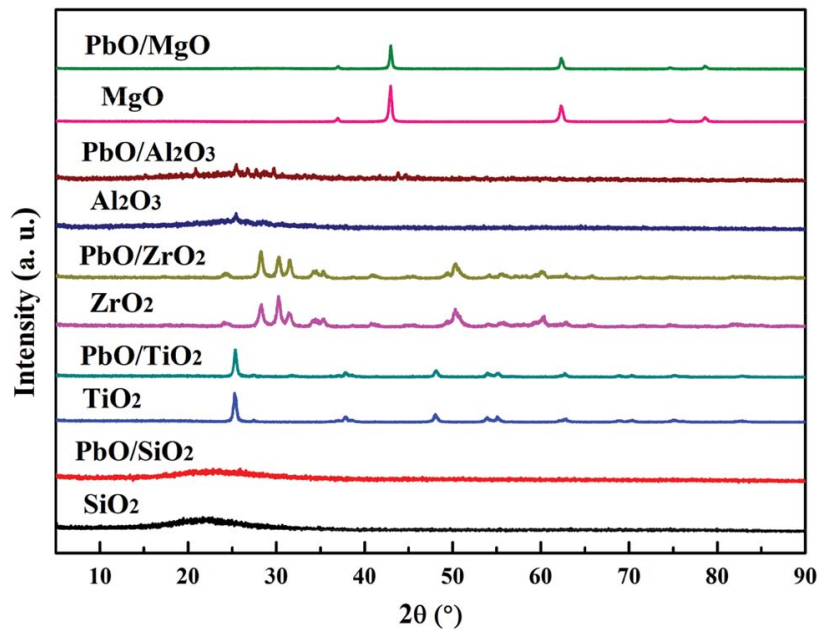

Fig. 1 XRD patterns of the catalysts and corresponding supports.

anatase $\mathrm{TiO}_{2}$, and analogously the characteristic peak ascribed to $\mathrm{PbO}$ phases was absent for $\mathrm{PbO} / \mathrm{TiO}_{2}$. $\mathrm{ZrO}_{2}$ displayed the existence of monoclinic $\left(2 \theta=30.3^{\circ}\right)$ and tetragonal $(2 \theta=24.3$ and $31.5^{\circ}$ ) zirconia phases, and $\mathrm{PbO} / \mathrm{ZrO}_{2}$ exhibited the same structure with that of $\mathrm{ZrO}_{2}$ support. The diffraction peak at 25.5 belonging to $\gamma-\mathrm{Al}_{2} \mathrm{O}_{3}$ support was clearly observed, ${ }^{32,33}$ while $\mathrm{PbO}$ crystalline phases appeared at 20.8, 25.4, 26.6, 27.7 and $29.7^{\circ}$ for $\mathrm{PbO} / \mathrm{Al}_{2} \mathrm{O}_{3}$. $\mathrm{PbO} / \mathrm{MgO}$ exhibited also the same crystalline structure with those of $\mathrm{MgO}$ support, and no $\mathrm{PbO}$ diffraction peak was observed. The XRD results suggested that the $\mathrm{PbO}$ active phases had better dispersion on the surface of $\mathrm{SiO}_{2}, \mathrm{TiO}_{2}$, $\mathrm{ZrO}_{2}$ and $\mathrm{MgO}$ supports in an amorphous state than that on $\mathrm{Al}_{2} \mathrm{O}_{3}$.

3.1.3 $\quad \mathrm{H}_{2}$-TPR characterization. $\mathrm{H}_{2}$-TPR measurement was conducted to investigate the reduction behaviors of $\mathrm{PbO}$ species over the catalysts. The $\mathrm{H}_{2}$-TPR profiles of both the catalysts and pure supports were shown in Fig. 2. Firstly, for $\mathrm{SiO}_{2}, \mathrm{ZrO}_{2}$ and $\mathrm{MgO}$ supports, there were no evident reduction peak appearances in the temperature ranges of $100-800{ }^{\circ} \mathrm{C}$. By contrast, the reduction characteristic peaks at 730 and $781{ }^{\circ} \mathrm{C}$ were observed for pure $\mathrm{TiO}_{2}$ and $\mathrm{Al}_{2} \mathrm{O}_{3}$, respectively. Secondly, for various $\mathrm{Pb}$ based catalysts, only one distinct reduction characteristic peak was observed in $\mathrm{PbO} / \mathrm{SiO}_{2}, \mathrm{PbO} / \mathrm{TiO}_{2}, \mathrm{PbO} / \mathrm{ZrO}_{2}$ and $\mathrm{PbO} /$ $\mathrm{MgO}$ respectively, suggesting that mainly $\mathrm{PbO}$ was reduced. As reported in the literatures, ${ }^{25,34}$ pure $\mathrm{PbO}$ revealed a clear reduction peak of $588{ }^{\circ} \mathrm{C}$, which was assigned to $\mathrm{PbO}$ species reduction. Therefore, these peaks in $\mathrm{PbO} / \mathrm{SiO}_{2}\left(552{ }^{\circ} \mathrm{C}\right), \mathrm{PbO} /$ $\mathrm{TiO}_{2}\left(591{ }^{\circ} \mathrm{C}\right), \mathrm{PbO} / \mathrm{ZrO}_{2}\left(348^{\circ} \mathrm{C}\right)$ and $\mathrm{PbO} / \mathrm{MgO}\left(410{ }^{\circ} \mathrm{C}\right)$ were typically ascribed to the reduction of highly dispersed surface $\mathrm{PbO}$ species, nevertheless, it was noteworthy that there were also obvious differences in the peak positions for them, suggesting that $\mathrm{PbO}$ loading onto different supports had a great influence on the reduction temperature of $\mathrm{PbO}$ species. Notably, the reduction temperature of $\mathrm{PbO}$ species on $\mathrm{SiO}_{2}, \mathrm{ZrO}_{2}$ and $\mathrm{MgO}$ supports were shifted to lower temperatures. This was mainly due to the strong interaction between $\mathrm{PbO}$ species and the supports which was favorable for the stability of the catalysts during reaction. Whereas in the case of $\mathrm{PbO} / \mathrm{TiO}_{2}$ the

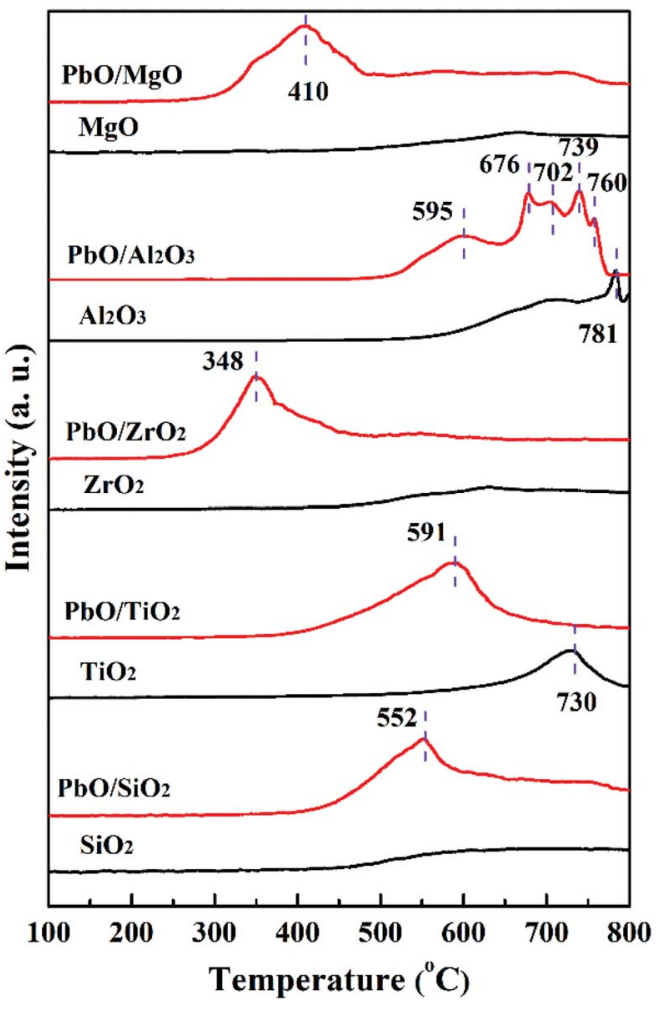

Fig. $2 \mathrm{H}_{2}$-TPR profiles of the catalysts and corresponding supports.

reduction peak shifted to a higher temperature and this was mainly due to the poor interaction between $\mathrm{PbO}$ and the $\mathrm{TiO}_{2}$ support. Thus, the results suggested that the interaction strengths between the active component and the different supports were remarkably different.

Thirdly, for $\mathrm{PbO} / \mathrm{Al}_{2} \mathrm{O}_{3}$, five reduction characteristic peaks appeared. The first reduction peak at $595{ }^{\circ} \mathrm{C}$ corresponded to the surface $\mathrm{PbO}$ specie reduction, and the second reduction peak at $676{ }^{\circ} \mathrm{C}$ might result from the reduction of the bulk PbO, as the XRD results displayed the existence of $\mathrm{PbO}$ crystalline diffraction peaks, which was primarily assigned to the weak interaction between $\mathrm{PbO}$ and the $\mathrm{Al}_{2} \mathrm{O}_{3}$ support so that the $\mathrm{PbO}$ species was difficult to reduce at a higher reduction temperature. The following three peaks with reduction temperatures at 702,739 and $760^{\circ} \mathrm{C}$ were probably associated with the reduction of the $\mathrm{Pb}-\mathrm{Al}$ mixed species formed via the interaction at high temperature $\left(>700{ }^{\circ} \mathrm{C}\right)$ of partially reduced $\mathrm{Pb}$-species and the support. ${ }^{35,36}$ Overall, according to the reduction temperatures of $\mathrm{PbO}$ species, it could be inferred that the interaction strengths between $\mathrm{PbO}$ and the supports were in the following order of $\mathrm{PbO} / \mathrm{ZrO}_{2}>\mathrm{PbO} / \mathrm{MgO}>\mathrm{PbO} / \mathrm{SiO}_{2}>\mathrm{PbO} / \mathrm{TiO}_{2}>\mathrm{PbO} / \mathrm{Al}_{2} \mathrm{O}_{3}$, which might lead to different catalytic properties.

3.1.4 TEM characterization. Fig. 3 displayed the TEM images of the catalysts. As shown in Fig. 3(A and a), $\mathrm{PbO} / \mathrm{SiO}_{2}$ mainly represented the spherical-like structure, and the $\mathrm{PbO}$ particles might be clearly observed, indicating that they were highly dispersed on the surface of the $\mathrm{SiO}_{2}$. For $\mathrm{PbO} / \mathrm{TiO}_{2}, \mathrm{PbO} /$ $\mathrm{ZrO}_{2}, \mathrm{PbO} / \mathrm{Al}_{2} \mathrm{O}_{3}$ and $\mathrm{PbO} / \mathrm{MgO}$ displayed in Fig. 3(B, b)-(E, e), their morphology were remarkably different from each other. 


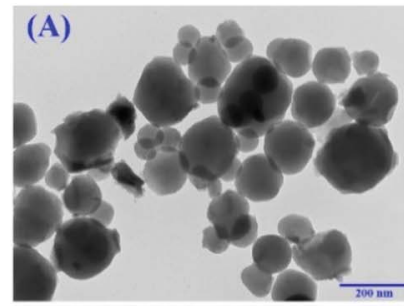

(B)

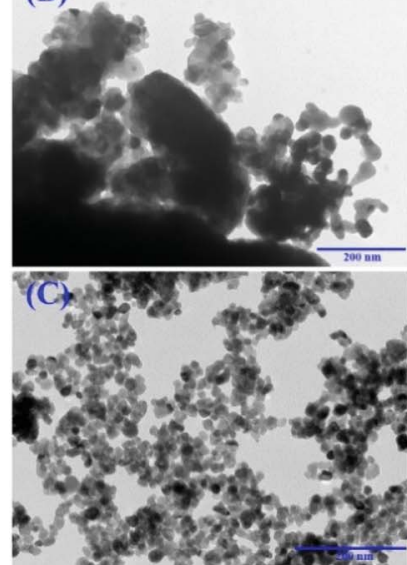

(D)

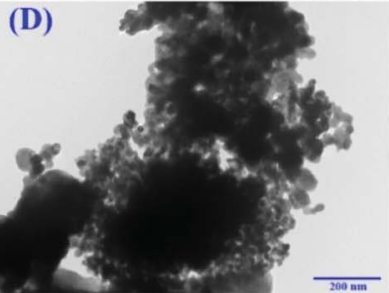

(E)

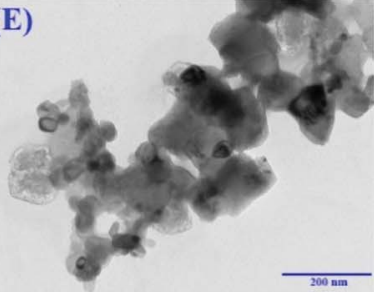

(d)

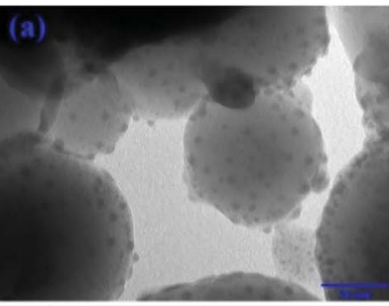

(b)
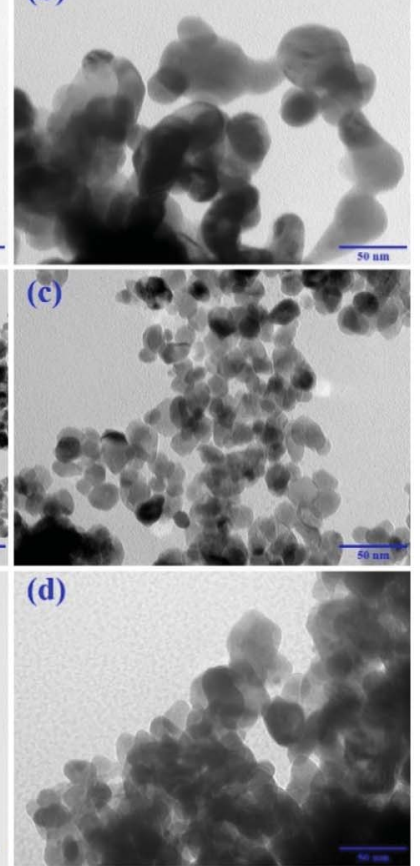

(e)

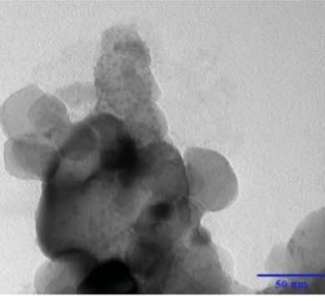

Fig. 3 TEM pictures of $\mathrm{PbO} / \mathrm{SiO}_{2}$ ( $\mathrm{A}$ and $\mathrm{a}$ ), $\mathrm{PbO} / \mathrm{TiO}_{2}(\mathrm{~B}$ and $\mathrm{b}$ ), $\mathrm{PbO}$ / $\mathrm{ZrO}_{2}\left(\mathrm{C}\right.$ and $\mathrm{C}$ ), $\mathrm{PbO} / \mathrm{Al}_{2} \mathrm{O}_{3}(\mathrm{D}$ and $\mathrm{d}$ ) and $\mathrm{PbO} / \mathrm{MgO}$ ( $\mathrm{E}$ and $\mathrm{e}$ ).

The diameters of all these catalysts were also not uniform, and the dissociation of $\mathrm{PbO}$ particles and the supports could not be detected by visual inspection. Comparatively speaking, $\mathrm{PbO} /$ $\mathrm{ZrO}_{2}$ exhibited a smaller particle size than the other catalysts.

3.1.5 XPS characterization. XPS analyses were employed to identify the chemical composition and states of the catalysts. The XPS survey spectrum verified the presence of $\mathrm{Pb}$ in the supported catalysts. As shown in Fig. 4(A), the definitive binding energy peak located at approximately $142.9-144.0 \mathrm{eV}$ and 137.9$139.2 \mathrm{eV}$ corresponded to $\mathrm{Pb} 4 \mathrm{f}_{5 / 2}$ and $\mathrm{Pb} 4 \mathrm{f}_{7 / 2},{ }^{23,37}$ indicating that $\mathrm{Pb}^{2+}$ species existed on the surface of these catalysts. Fig. 4(B) showed that the $\mathrm{O} 1 \mathrm{~s}$ spectra of the catalysts (except $\mathrm{PbO} / \mathrm{Al}_{2} \mathrm{O}_{3}$ catalyst) could be deconvoluted into two Gaussian peaks $\left(\mathrm{O}_{\mathrm{I}}\right.$ and $\left.\mathrm{O}_{\text {III }}\right)$. In general, $\mathrm{O}_{\mathrm{I}}$ was ascribed to the lattice oxygen in the literature, ${ }^{28,34}$ and $\mathrm{O}_{\mathrm{II}}$ was related to the adsorbed oxygen species on the catalyst surface. The binding energy of

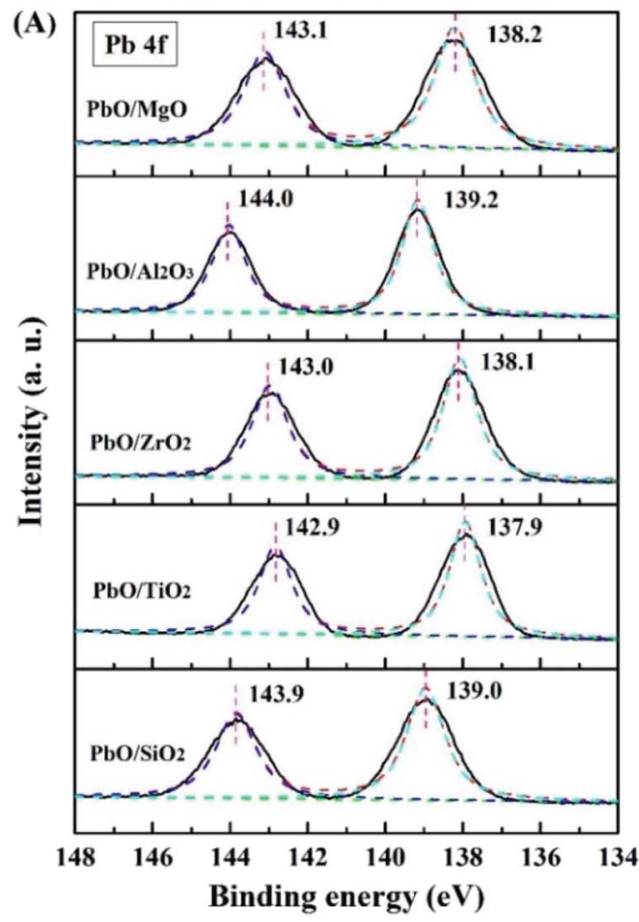

(B)

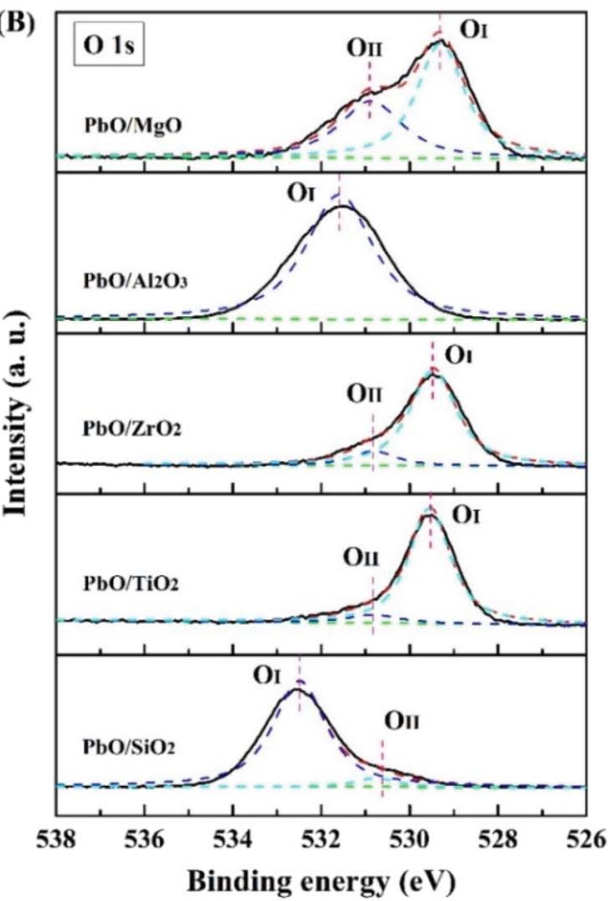

Fig. 4 XPS spectra of the catalysts.

the $\mathrm{O}$ 1s spectra was different in each catalyst, which was probably due to the different support properties for the supported $\mathrm{Pb}$-based catalysts.

3.1.6 $\mathbf{N H}_{3}$-TPD characterization. The process of MPC disproportionation to produce DPC was mainly dependent on the acidity of the catalyst. Herein $\mathrm{NH}_{3}$-TPD was carried out for measuring the acidic properties of the catalysts. The $\mathrm{NH}_{3}$-TPD profiles were displayed in Fig. 5. According to the literatures, ${ }^{38,39}$ 


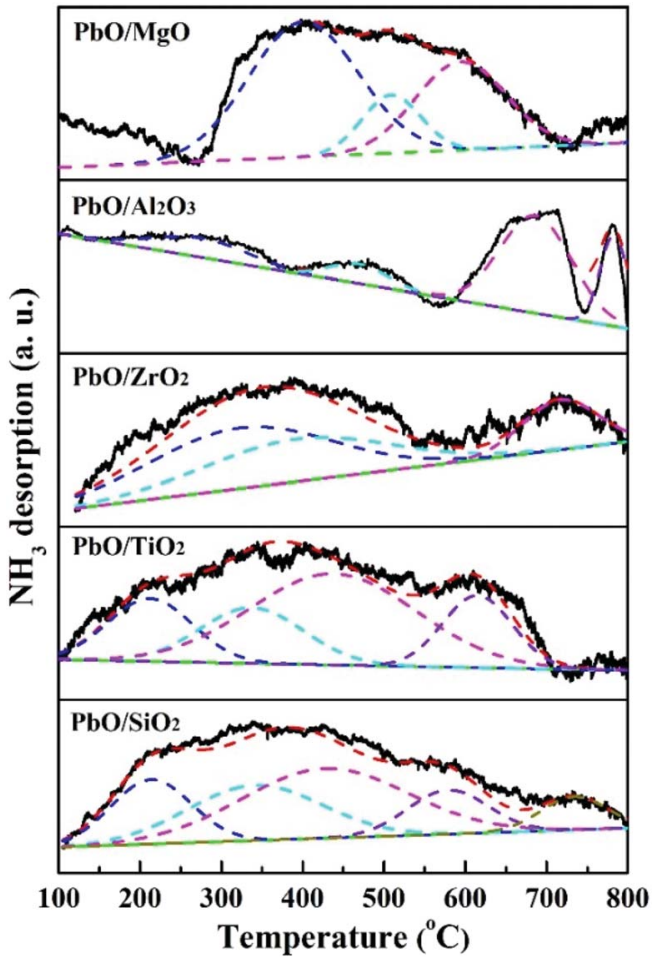

Fig. $5 \mathrm{NH}_{3}$-TPD profiles of the catalysts.

the acid sites of the catalysts were usually classified based on desorption temperature range such as weak (around 100-200 ${ }^{\circ} \mathrm{C}$ ), medium (around $200-400{ }^{\circ} \mathrm{C}$ ), and strong (above $400{ }^{\circ} \mathrm{C}$ ) acidic sites, respectively. As shown in Fig. 3 , the acidity of the catalysts depended on the nature of the supports, and $\mathrm{PbO} / \mathrm{SiO}_{2}$, $\mathrm{PbO} / \mathrm{TiO}_{2}$ and $\mathrm{PbO} / \mathrm{ZrO}_{2}$ exhibited remarkable and broad $\mathrm{NH}_{3}$ desorption peaks, suggesting the wide distribution of acid strengths from weak, medium and strong acid sites respectively. For $\mathrm{PbO} / \mathrm{MgO}$ catalyst, only one strong high-temperature $\mathrm{NH}_{3}$ desorption peak at the range of 250 to $700{ }^{\circ} \mathrm{C}$ was detected, suggesting a strong acid property. $\mathrm{PbO} / \mathrm{Al}_{2} \mathrm{O}_{3}$ showed much stronger $\mathrm{NH}_{3}$ desorption peak in the high-temperature region, indicating more strong acidic sites existed on the surface. Besides, the acidity data was also calculated and the results were given in Table 2. Clearly, the total acid amount in $\mathrm{PbO} /$ $\mathrm{MgO}$ was remarkably higher than those of other catalysts, and followed the sequence of $\mathrm{PbO} / \mathrm{MgO}>\mathrm{PbO} / \mathrm{ZrO}_{2}>\mathrm{PbO} / \mathrm{SiO}_{2}>$ $\mathrm{PbO} / \mathrm{TiO}_{2}>\mathrm{PbO} / \mathrm{Al}_{2} \mathrm{O}_{3}$. According to previous studies, the

Table 2 The acidity of the catalysts determined by $\mathrm{NH}_{3}-\mathrm{TPD}$

\begin{tabular}{|c|c|c|c|c|c|}
\hline \multirow[b]{2}{*}{ Catalysts } & \multicolumn{3}{|c|}{$\begin{array}{l}\text { Acid amounts (mmol } \\
\left.\mathrm{g}^{-1}\right)\end{array}$} & \multirow{2}{*}{$\begin{array}{l}\text { Total acid amounts } \\
\left(\mathrm{mmol} \mathrm{g}^{-1}\right)\end{array}$} & \multirow[b]{2}{*}{$A_{\mathrm{L}} / A_{\mathrm{B}}$ ratio } \\
\hline & Weak & Medium & Strong & & \\
\hline $\mathrm{PbO} / \mathrm{MgO}$ & 0 & 0.030 & 0.048 & 0.078 & 0.582 \\
\hline $\mathrm{PbO} / \mathrm{Al}_{2} \mathrm{O}_{3}$ & 0 & 0.001 & 0.009 & 0.010 & - \\
\hline $\mathrm{PbO} / \mathrm{ZrO}_{2}$ & 0.004 & 0.019 & 0.029 & 0.052 & 0.610 \\
\hline $\mathrm{PbO} / \mathrm{TiO}_{2}$ & 0.002 & 0.004 & 0.017 & 0.023 & 0.579 \\
\hline $\mathrm{PbO} / \mathrm{SiO}_{2}$ & 0.002 & 0.014 & 0.020 & 0.036 & 0.489 \\
\hline
\end{tabular}

acidity of the catalysts was correlated with the activity, thus the high acidity of the catalyst was beneficial for the activity.

3.1.7 Py-IR characterization. The type of acid sites was performed by pyridine adsorption FT-IR spectroscopy. Fig. 6 showed the Py-IR spectra of the catalysts. As shown in Fig. 6, $\mathrm{PbO} / \mathrm{SiO}_{2}, \mathrm{PbO} / \mathrm{TiO}_{2}, \mathrm{PbO} / \mathrm{ZrO}_{2}$ and $\mathrm{PbO} / \mathrm{MgO}$ exhibited two remarkable absorption peaks at around 1438-1446 and 1584$1596 \mathrm{~cm}^{-1}$, which were attributed to Lewis and Brønsted acidic sites, respectively. ${ }^{40,41}$ However, for $\mathrm{PbO} / \mathrm{Al}_{2} \mathrm{O}_{3}$, only one absorption peak was displayed at $1446 \mathrm{~cm}^{-1}$ that suggested the presence of only Lewis acidic sites. Meanwhile, the concentration ratio of Lewis to Brønsted acid sites was calculated by semiquantitative analysis based on the relative peak area corresponding to Lewis and Brønsted acidity $\left(A_{\mathrm{L}} / A_{\mathrm{B}}\right)$ in Table 2. Apparently, the $A_{\mathrm{L}} / A_{\mathrm{B}}$ ratios were higher for $\mathrm{PbO} / \mathrm{ZrO}_{2}$ and $\mathrm{PbO} /$ MgO compared to others, and combined with the acid amount results determined by $\mathrm{NH}_{3}$-TPD, which indicated that $\mathrm{PbO} / \mathrm{ZrO}_{2}$ and $\mathrm{PbO} / \mathrm{MgO}$ contained much more Lewis acidic sites.

\subsection{Results of the catalytic performance evaluation}

The catalytic performance evaluation results for MPC disproportionation over the catalysts were revealed in Table 3. Pure supports were basically inactive under the current studies, while $\mathrm{PbO}$ loading on these supports exhibited considerably different catalytic performances. The catalytic activities of $\mathrm{PbO} / \mathrm{MgO}$ and $\mathrm{PbO} / \mathrm{ZrO}_{2}$ were close and obviously higher than those of $\mathrm{PbO} /$ $\mathrm{SiO}_{2}, \mathrm{PbO} / \mathrm{Al}_{2} \mathrm{O}_{3}$ and $\mathrm{PbO} / \mathrm{TiO}_{2}$, and the sequence of the activities for the MPC conversion was as follows: $\mathrm{PbO} / \mathrm{MgO}>\mathrm{PbO} /$ $\mathrm{ZrO}_{2}>\mathrm{PbO} / \mathrm{SiO}_{2}>\mathrm{PbO} / \mathrm{Al}_{2} \mathrm{O}_{3}>\mathrm{PbO} / \mathrm{TiO}_{2}$. Previous studies displayed that the BET surface area and acidity of catalyst played significant role in the catalytic activity and product selectivity. Nevertheless, this order of the activity was not correlated with the sequence of BET surface area, indicating that the surface area might be not a main factor determining the activity. Therefore, the catalytic activity might be closely related to the acidity. Combining with the characteristic results of Py-IR and $\mathrm{NH}_{3}$-TPD, the relationship between the activity and Lewis acidity was displayed in Fig. 7. It was clear that the activity depended on the acidic site, and the more Lewis acid site was,

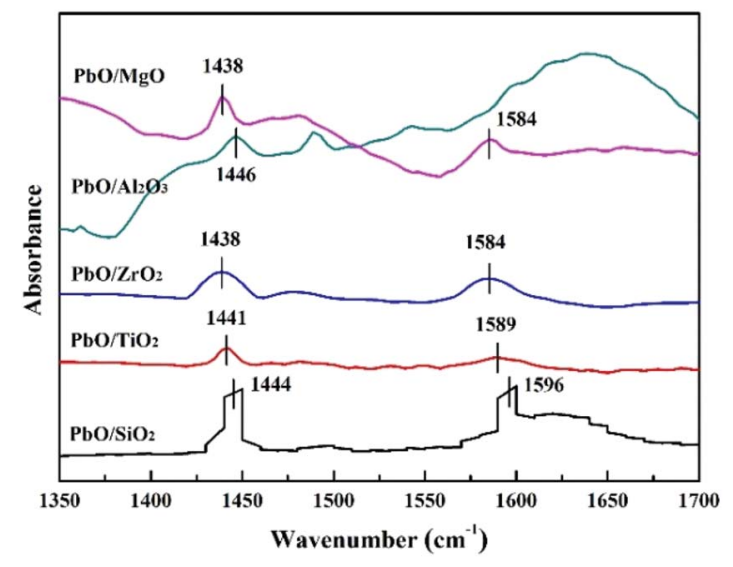

Fig. 6 Py-IR spectra of the catalysts. 
Table 3 Catalytic performance results of MPC disproportionation over the catalysts ${ }^{a}$

\begin{tabular}{lllll}
\hline & & \multicolumn{2}{c}{ Yield/\% } & \\
\cline { 3 - 4 } Catalysts & MPC conversion/\% & DPC & Anisole & DPC selectivity/\% \\
\hline $\mathrm{PbO} / \mathrm{MgO}$ & 60.1 & 56.0 & 4.1 & 93.2 \\
$\mathrm{PbO} / \mathrm{ZrO}_{2}$ & 56.3 & 55.2 & 1.1 & 98.0 \\
$\mathrm{PbO} / \mathrm{SiO}_{2}$ & 47.7 & 46.2 & 1.6 & 96.9 \\
$\mathrm{PbO} / \mathrm{Al}_{2} \mathrm{O}_{3}$ & 30.2 & 26.5 & 3.7 & 87.7 \\
$\mathrm{PbO} / \mathrm{TiO}_{2}$ & 24.3 & 22.9 & 1.4 & 94.2
\end{tabular}

${ }^{a}$ Reaction conditions: MPC $(150 \mathrm{mmol})$, catalyst $(1.2 \mathrm{~g}), 200{ }^{\circ} \mathrm{C}, 2.5 \mathrm{~h}$. Anisole was a small amount of byproduct.

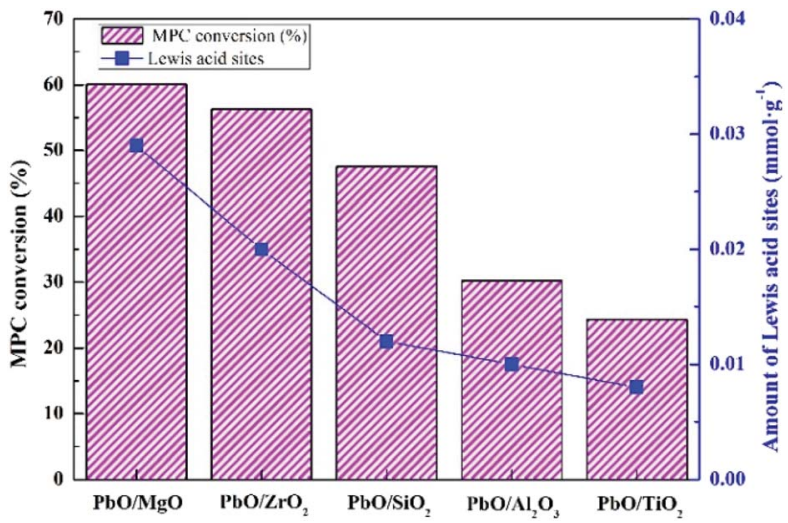

Fig. 7 MPC conversion and Lewis acid sites on the catalysts.

the higher the activity was. And the decrease sequence of MPC conversion was in accordance with the order of the Lewis acid site, suggesting that the Lewis acid was the critical factor to determine the catalytic activity. What's more, although the highest DPC yield was obtained over $\mathrm{PbO} / \mathrm{MgO}$ due to the acidity of this catalyst being the highest among all the catalysts, yet it was also noteworthy that a strong acid strength could induce the decarboxylation decomposition of MPC into the byproduct anisole. Therefore, it could be ascertained that the higher anisole content was mainly due to its excessively strong acidity. ${ }^{20}$ Moreover, $\mathrm{PbO} / \mathrm{Al}_{2} \mathrm{O}_{3}$ with more strong acid strength exhibited the higher anisole content, which further testified the reason. Thus, the results also suggested that medium and moderately strong acidic sites were favorable for the higher DPC selectivity.

\subsection{Recyclability of the catalysts}

Recycling experiments of the catalysts were performed to check the stability. After each run, the catalysts were separated by filtration, washed thoroughly with DMC and dried in vacuum at $110{ }^{\circ} \mathrm{C}$ overnight, and then reused for next cycle reaction. As displayed in Fig. 8, there was no remarkable change in the MPC conversion and yield DPC after three cycles over $\mathrm{PbO} / \mathrm{MgO}$ and $\mathrm{PbO} / \mathrm{ZrO}_{2}$. However, for $\mathrm{PbO} / \mathrm{SiO}_{2}, \mathrm{PbO} / \mathrm{Al}_{2} \mathrm{O}_{3}$ and $\mathrm{PbO} / \mathrm{TiO}_{2}$ catalysts, the catalytic activities decreased gradually in the
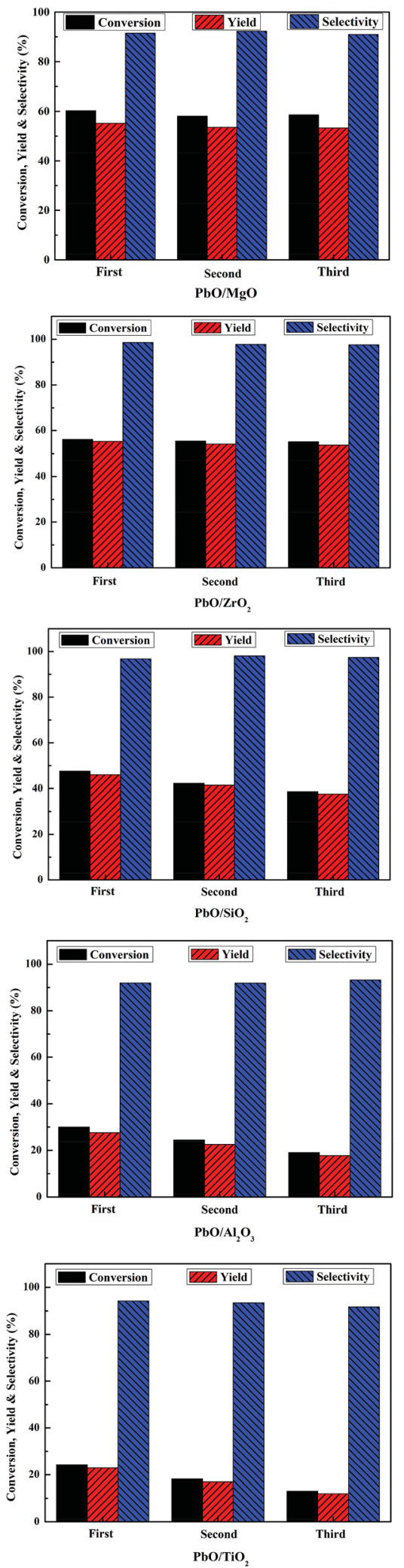

Fig. 8 Reusability of the catalysts. Reaction conditions: MPC (150 $\mathrm{mmol})$, catalyst $(1.2 \mathrm{~g}), 200^{\circ} \mathrm{C}, 2.5 \mathrm{~h}$.

succeeding three runs, suggesting that $\mathrm{PbO} / \mathrm{MgO}$ and $\mathrm{PbO} / \mathrm{ZrO}_{2}$ possessed much better reusability than $\mathrm{PbO} / \mathrm{SiO}_{2}, \mathrm{PbO} / \mathrm{Al}_{2} \mathrm{O}_{3}$ and $\mathrm{PbO} / \mathrm{TiO}_{2}$. 
In heterogeneous catalysis, the leaching of active component was often the main reason which decreased the activity for further reuse. Therefore, the recovered catalysts were detected by ICP-OES analysis (Table $\mathrm{S} 1 \dagger$ ), and the content of $\mathrm{Pb}$ in the fresh and the third reused catalyst showed that $\mathrm{Pb}$ content had no significant loss over $\mathrm{PbO} / \mathrm{MgO}$ and $\mathrm{PbO} / \mathrm{ZrO}_{2}$, but dropped markedly over $\mathrm{PbO} / \mathrm{SiO}_{2}, \mathrm{PbO} / \mathrm{Al}_{2} \mathrm{O}_{3}$ and $\mathrm{PbO} / \mathrm{TiO}_{2}$, respectively. Hence, the leaching loss of $\mathrm{Pb}$ might lead to the decrease of catalytic activities for the recovered $\mathrm{PbO} / \mathrm{SiO}_{2}, \mathrm{PbO} / \mathrm{Al}_{2} \mathrm{O}_{3}$ and $\mathrm{PbO} / \mathrm{TiO}_{2}$ catalysts. Combined with the characteristic results of $\mathrm{H}_{2}$-TPR, the excellent recyclability of $\mathrm{PbO} / \mathrm{MgO}$ and $\mathrm{PbO} / \mathrm{ZrO}_{2}$ was possibly attributed to their strong interactions of the supports with highly dispersed $\mathrm{Pb}$, which was potentially important for practical applications. Besides, the recovered catalysts after the third use were also detected by XRD characterization (Fig. S1 $\dagger$ ). The result indicated that the diffraction peaks of the third reused catalysts were basically identical to those of the fresh catalysts, suggesting that with the exception of $\mathrm{PbO} / \mathrm{Al}_{2} \mathrm{O}_{3}, \mathrm{PbO}$ was still amorphous or microcrystalline states in the recovered catalysts. Therefore, $\mathrm{MgO}$ and $\mathrm{ZrO}_{2}$ might be suitable and promising support materials for the better preparation of $\mathrm{Pb}$-based catalysts to transform MPC disproportionation to efficiently synthesize DPC in comparison with $\mathrm{SiO}_{2}, \mathrm{Al}_{2} \mathrm{O}_{3}$ and $\mathrm{TiO}_{2}$.

\section{Conclusions}

In summary, the support nature modified the structural properties of $\mathrm{Pb}$ catalysts and exerted marked influence on their catalytic performances. The catalysts were characterized by physicochemical techniques, and the results showed that $\mathrm{PbO}$ was dispersed better on $\mathrm{SiO}_{2}, \mathrm{TiO}_{2}, \mathrm{ZrO}_{2}$ and $\mathrm{MgO}$ than $\mathrm{Al}_{2} \mathrm{O}_{3}$, and the stronger metal-support interaction was obtained over $\mathrm{MgO}$ and $\mathrm{ZrO}_{2}$. The active results showed that the catalytic performances over $\mathrm{MgO}$ and $\mathrm{ZrO}_{2}$ to load $\mathrm{Pb}$ catalysts were significantly superior to those of $\mathrm{SiO}_{2}, \mathrm{Al}_{2} \mathrm{O}_{3}$ and $\mathrm{TiO}_{2}$, because of the higher active component dispersion and more Lewis acid active sites. Furthermore, the excellent recyclability in the case of $\mathrm{PbO} / \mathrm{MgO}$ and $\mathrm{PbO} / \mathrm{ZrO}_{2}$ was potentially important in industrial application. Thus, from this study it could be noted that the more Lewis acid site was present, the more the activity was, and the nature of the support was a key parameter for MPC disproportionation.

\section{Conflicts of interest}

There are no conflicts to declare.

\section{Acknowledgements}

The authors thank the financial support provided by the National High Technology Research and Development Program of China (863 program, No. 2013AA031703), National Natural Science Foundation of China (No. 21808048), Project funded by China Postdoctoral Science Foundation (2018M632782), the Key Project of Science and Technology Program of Henan Province (182102210050), the Science Research Start-up Fund of Henan
Institute of Science and Technology (2015031) and the Project funded by Postdoctoral Science Foundation of Henan Province.

\section{Notes and references}

1 M. C. Figueiredo, V. Trieu, S. Eiden, J. Heijl and M. T. M. Koper, ACS Catal., 2018, 8, 3087-3090.

2 S. Bahrami, S. N. Khorasani, A. Abdolmaleki, S. M. Davoodi and A. Farzan, J. Elastomers Plast., 2018, 50, 107-123.

3 G. Contreras-Zarazúa, J. A. Vázquez-Castillo, C. RamírezMárquez, G. A. Pontis, J. G. Segovia-Hernández and J. R. Alcántara-Ávila, Energy, 2017, 165, 637-649.

4 A. Gawdzik, A. Mederska and T. Mederski, Polym. Bull., 2017, 74, 1553-1571.

5 R. Kaneg, H. Ogihar and I. Yamanaka, Catal. Sci. Technol., 2016, 6, 6002-6010.

6 Y. Ono, Appl. Catal., A, 1997, 155, 133-166.

7 W. B. Kim, U. A. Joshi and J. S. Lee, Ind. Eng. Chem. Res., 2004, 43, 1897-1914.

8 M. Peng, X. Yang, J. X. Wu, H. Yuan, C. F. Yin and Y. X. Wu, Chem. Ind. Chem. Eng. Q., 2017, 23, 421-429.

9 G. Z. Fan, H. T. Zhao, Z. X. Duan, T. Fang, M. H. Wan and L. N. He, Catal. Sci. Technol., 2011, 1, 1138-1141.

10 Y. Gao, Z. H. Li, K. M. Su and B. W. Cheng, Chem. Eng. J., 2016, 301, 12-18.

11 C. Z. Wang, T. Guo, M. M. Sun, C. H. Li, M. Guo, C. L. Li and Q. Wang, Sci. Adv. Mater., 2018, 10, 779-784.

12 S. L. Wang, R. Z. Tang, Y. Z. Zhang, T. Chen and G. Y. Wang, Chem. Eng. Sci., 2015, 138, 93-98.

13 S. H. Huang, B. Yan, S. P. Wang and X. B. Ma, Chem. Soc. Rev., 2015, 44, 3079-3116.

14 Z. L Xiao, H. Yang, H. Zhang, T. Chen and G. Y. Wang, Chem. Pap., 2018, 72, 2347-2352.

15 S. Han, M. Luo, X. L. Zhou, Z. He and L. P. Xiong, Ind. Eng. Chem. Res., 2012, 51, 5433-5437.

16 Y. T. Kim and E. D. Park, Appl. Catal., A, 2009, 356, 211-215. 17 W. Q. Zhou, X. Q. Zhao, Y. J. Wang and J. Y. Zhang, Appl. Catal., A, 2004, 260, 19-24.

18 Z. H. Fu and Y. Ono, J. Mol. Catal. A: Chem., 1997, 118, 293299.

19 S. L. Wang, Y. Z. Zhang, Y. Chen, R. Z. Tang, T. Chen and G. Y. Wang, Chem. J. Chin. Univ., 2014, 35, 2177-2181.

20 S. L. Wang, T. Chen, G. Y. Wang, C. X. Cui, H. Y. Niu and C. G. Li, Appl. Catal., A, 2017, 540, 1-6.

21 Z. Luo, Y. Wang, Y. Zhang, D. Wei, J. Jiang and G. Y. Wang, Fine Chem., 2008, 25, 813-816.

22 S. L. Wang, Y. Z. Zhang, T. Chen and G. Y. Wang, J. Mol. Catal. A: Chem., 2015, 398, 248-254.

23 S. L. Wang, C. G. Li, Z. L. Xiao, T. Chen and G. Y. Wang, J. Mol. Catal. A: Chem., 2016, 420, 26-33.

24 Q. Fu, Y. C. Ou, Y. Zeng and G. Y. Wang, Chem. Ind. Eng. Prog., 2017, 36, 2748-2755.

25 S. L. Wang, H. Y. Niu, M. J. Guo, J. J. Wang, T. Chen and G. Y. Wang, Mol. Catal., 2019, 468, 117-124.

26 E. Leino, N. Kumar, P. Mäki-Arvela, A. R. Rautio, J. Dahl, J. Roine and J. P. Mikkola, Catal. Today, 2018, 306, 128-137. 
27 C. José, M. V. Toledo, P. Nicolás, V. Lasalle, M. L. Ferreira and L. E. Briand, Catal. Sci. Technol., 2018, 8, 3513-3526.

28 X. X. Wang, W. Chen, T. J. Lin, J. Li, F. Yu, Y. L. An, Y. Y. Dai, H. Wang, L. S. Zhong and Y. H. Sun, Chin. J. Catal., 2018, 39, 1869-1880.

29 J. S. Wang and H. Liu, RSC Adv., 2016, 6, 2374-2378.

30 G. Tsilomelekis, A. Christodoulakis and S. Boghosian, Catal. Today, 2007, 127, 139-147.

31 K. V. R. Chary, B. R. Rao and V. S. Subrahmanyam, Appl. Catal., 1991, 74, 1-13.

32 L. Fratalocchi, C. G. Visconti, L. Lietti, G. Groppi, E. Tronconi, E. Roccaro and R. Zennaro, Catal. Sci. Technol., 2016, 6, 6431-6440.

33 M. Jones, G. J. Hutchings, D. J. Willock, J. Scott and S. H. Taylor, J. Catal., 2018, 364, 102-111.
34 S. L. Wang, H. Y. Niu, J. J. Wang, T. Chen and G. Y. Wang, J. Alloys Compd., 2019, 777, 18-25.

35 L. Fratalocchi, C. G. Visconti, L. Lietti, N. Fischer and M. Claeys, Appl. Catal., A, 2018, 556, 92-103.

36 Y. H. Wu, W. Q. Xu, Y. Yang, J. Wang and T. Y. Zhu, Catal. Sci. Technol., 2018, 8, 297-306.

37 B. Niu and Z. M. Xu, Green Chem., 2019, 21, 874-884.

38 I. Prymak, O. Prymak, J. H. Wang, V. N. Kalevaru, A. Martin, U. Bentrup and S. Wohlrab, ChemCatChem, 2018, 10, 391394.

39 L. H. Chagas, C. R. V. Matheus, P. C. Zonetti and L. G. Appel, Mol. Catal., 2018, 458, 272-279.

40 K. Wang, M. Dong, X. J. Niu, J. F. Li, Z. F. Qin, W. B. Fan and J. G. Wang, Catal. Sci. Technol., 2018, 8, 5646-5656.

41 S. Pyen, E. Hong, M. Shin, Y. W. Suh and C. H. Shin, Mol. Catal., 2018, 448, 71-77. 